\title{
Conservative Follow-up of Severely Displaced Distal Radial Metaphyseal Fractures in Children
}

Deniz Akar ${ }^{1}$, Cenk Köroğlu ${ }^{2}$, Serkan Erkus ${ }^{3}$, Ali Turgut ${ }^{4}$, Önder Kalenderer ${ }^{5}$

1. Department of Orthopaedics and Traumatology, Milas State Hospital, İzmir, TUR 2. Department of Orthopaedics and Traumatology, Ardahan State Hospital, Ardahan, TUR 3. Department of Orthopaedics and Traumatology, Tepecik Training and Research Hospital, Izmir, TUR 4. Department of Orthopaedics and Traumatology, Tepecik Training and Research Hospital, Istanbul, TUR 5. Department of Orthopaedics and Traumatology, Tepecik Training and Research Hospital, İzmir, TUR

Corresponding author: Ali Turgut, draliturgutort@yahoo.com.tr

\begin{abstract}
Introduction

Distal radius fractures are the most frequent fractures seen in pediatric population and usually treated with closed reduction and casting. However, there is a risk of reduction loss and/or angulations in distal radial metaphyseal fractures. The purpose of this study is to evaluate the radiological and functional results of pediatric patients with distal radius metaphyseal fractures in which excessive displacement and/or angulations were accepted and to question upper acceptable limits in light of current literature.
\end{abstract}

\section{Methods}

Patients between five and 15 years of age with displaced distal radius fractures who were treated conservatively with significant angulation or translation were included in this study. Patients' demographic data were gathered from hospital's digital database. Clinical and radiological evaluations of all patients were done prospectively based on the last outpatient clinic control. Range of motion of wrist and elbow joint was measured with a goniometry, neurovascular status was documented, muscle strength was assessed and finally existing deformity measurements were performed clinically. Radiological evaluation was performed on pre-reduction, post-reduction, cast removal, 6th and 12th months and final examination radiographs. All measured values were compared with uninjured side. Radiologically, the percentage of translation, the amount of angulations, the distance from the fracture to the epiphyseal line, and the radius lengths were measured. Radial inclination and palmar tilt angles as well as ulnar variance and residual angulation were measured in both antero-posterior (AP) and lateral forearm radiographs. The Mann-Whitney U test was used to compare the variables in SPSS version 21. $\mathrm{p}<0.05$ was considered statistically significant.

\section{Results}

Twenty-nine patients with a mean age of $8.8 \pm 3.1$ years were included in this study. The mean follow-up duration was $17.4 \pm 6.7$ months. Compared to the uninjured side, in 24 (83\%) patients, there were no limitations on wrist movements except five patients in forearm pronation clinically. In patients with redisplacement, the mean displacement occurrence time was $13.3 \pm 4.9$ (7-21) days. The translational and/or angulations in AP and lateral radiographs fully remodeled at the end of 6th month.

\section{Conclusion}

This study demonstrates that radial and dorsal angular deformities up to $39^{\circ}$ and $22^{\circ}$ volar angulation and complete displacement correct fully in children up to 10 years old. In children between 10 and 15 years, the dorsal angulation up to $38^{\circ}$, radial angulation up to $23^{\circ}$, and volar angulation up to $16^{\circ}$ are acceptable for remodeling capacity of the child.

\section{Categories: Orthopedics}

Keywords: distal radial fractures, remodeling, conservative treatment, children

\section{Introduction}

Distal radius fractures are the most frequent fractures seen in pediatric population (20.2\%) and constitute approximately $1 / 6$ of the fractures treated in emergency department. The distal radial physis and distal ulnar physis are responsible for 75 to $80 \%$ and $20 \%$ of the longitudinal growth, respectively [1,2]. The rapid growth feature increases fracture tendency at the lower end of the radius, because distal metaphysis is relatively weak due to continuous remodeling. Fractures are seen especially in pubertal growth ages (11-14 years in males, 8-11 years in females) and in spring and summer months when physical activity increases $[3,4]$. Displaced distal radius fractures are usually treated with closed reduction and casting [5]. Prevention of reduction loss is the main issue in conservative treatment [6]. 
The treatment of pediatric patients with an angulated distal radius fracture due to reasons such as late presentation or malpositioned healing fracture is unclear. Because they will result in possible functional impairment if not align, some authors suggest recurrent closed reduction maneuvers because of possible functional impairment $[7,8]$. Conversely, some authors report that accepting at the current position without additional maneuver is proper approach in order to avoid potential physeal injury. They suggest waiting until skeletal maturity and then performing corrective osteotomy if it is still necessary $[1,2]$.

Orthopedic surgeons are prone to perform more aggressive treatment modalities in pediatric patients' fractures nowadays. Acceptance limits for conservative treatments are decreasing and surgical indications are expanding. The purpose of this study is to evaluate the radiological and functional results of pediatric patients with distal radius metaphyseal fractures in which excessive displacement and/or angulation was accepted and to question upper acceptable limits in light of the current literature.

\section{Materials And Methods}

Pediatric patients with distal radius metaphyseal fractures treated in authors' institution between 2012 and 2014 were retrospectively reviewed. Institutional review board approved the study protocol and this study was carried out in accordance with the ethical standards laid down in the 1964 Declaration of Helsinki and its later amendments. Patients between 5 and 15 years of age with displaced distal radius fractures who were treated conservatively with significant angulation or translation were included in this study. The reasons for acceptance of displacement were: patients with systemic diseases such as upper respiratory tract infections which are contraindication for general anesthesia, occurrence of reduction loss with late presentation and finally patients with neglected injuries who were referred from other hospitals. Patients who were followed less than one year and patients who rejected to participate in the study were excluded.

Patients' demographic data were gathered from hospital's digital database. Radiological analysis was performed by using Picture Archiving and Communication System (PACS). Clinical and radiological evaluations of all patients were done prospectively based on the last outpatient clinic control. All cases were treated with long arm plaster after reduction. In all cases, long arm casts were changed to short arm form after three to four weeks according to radiological fracture healing findings (callus formation occurrence in at least two cortices). Once the cast was removed, wrist and elbow movements started. It was suggested to avoid sports activities for three months.

As a standard protocol, the cases were invited to the outpatient clinic for the radiological control in every week during the first month, at the time of cast removal and at six months intervals afterwards. After removal of the cast, range of motion of wrist and elbow joints was measured with a goniometry, neurovascular status was documented, muscle strength was assessed and finally existing deformity measurements were performed clinically. Radiological evaluation was performed on pre-reduction, postreduction, cast removal, sixth and twelfth months and final examination radiographs. All measured values were compared with uninjured side. Radiologically, the percentage of translation, the amount of angulations, the distance from the fracture to the epiphyseal line, and the radius lengths were measured. Radial inclination and palmar tilt angles as well as ulnar variance and residual angulations were measured in both anterior-posterior (AP) and lateral forearm radiographs (Figure 1). 


\section{Cureus}

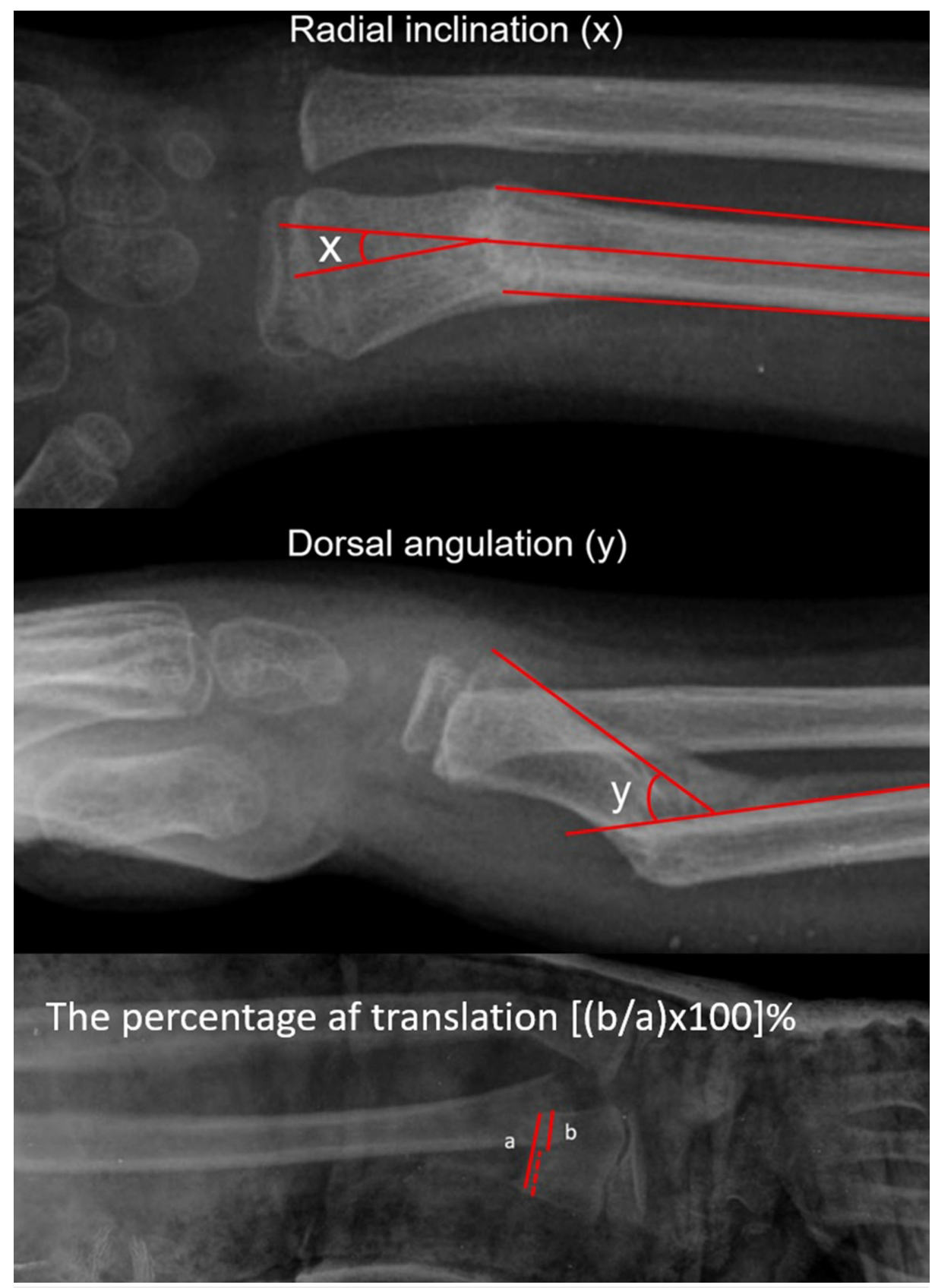

FIGURE 1: Figures demonstrating the method of measurements of angulations and translation. (a) Measurement of radial inclination, (b) dorsal angulation and (c) the percentage of translation.

After removal of the cast, the residual angulations were measured in accordance with the distance of the long axis of the proximal fracture fragment perpendicular to the radial epiphyseal line (Figure 2). The amount of fracture angulations was measured by an independent trauma surgeon. 


\section{Cureus}
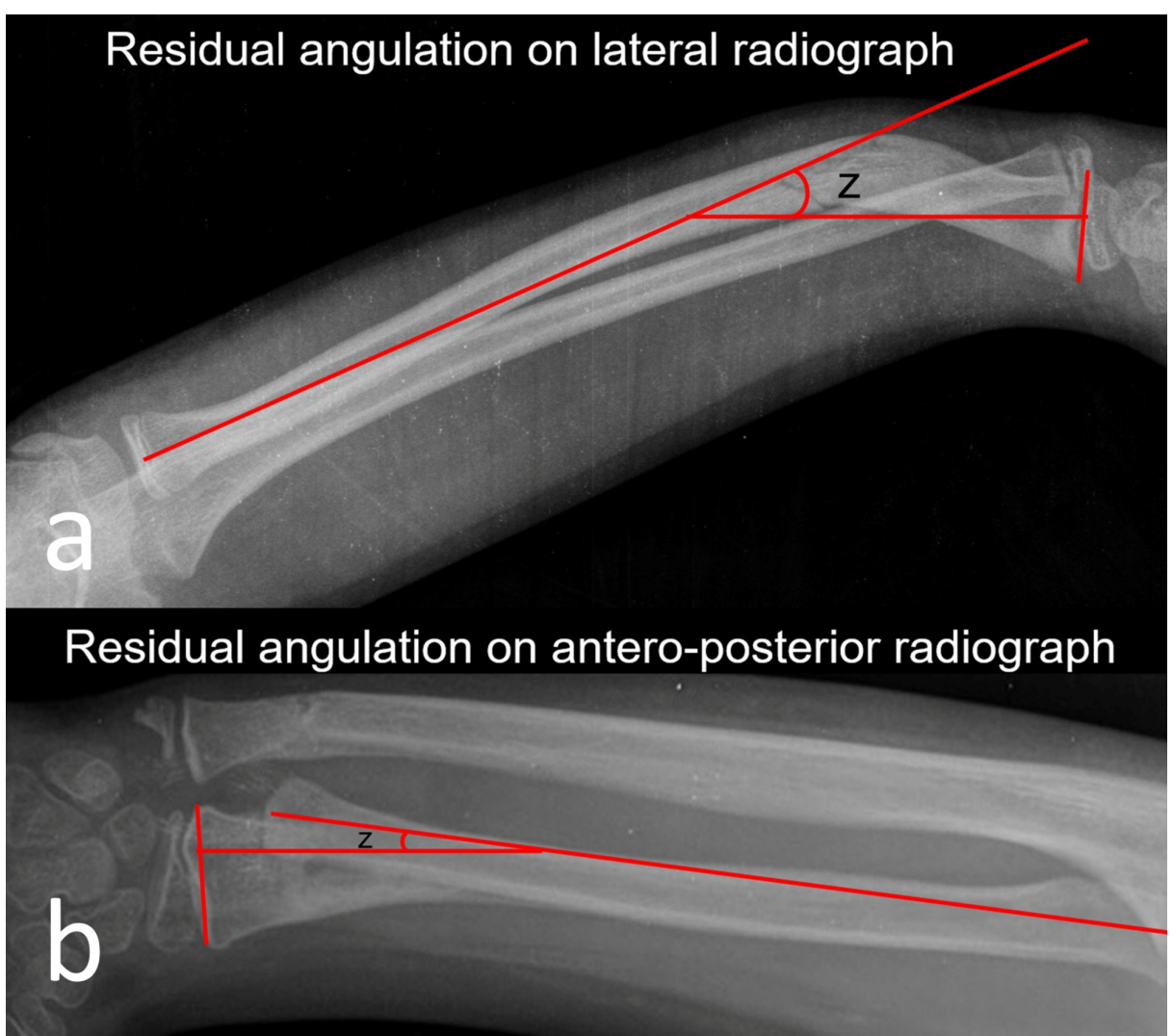

FIGURE 2: References about measurement of residual angulations. (a) Measurement of residual angulation on lateral radiograph, and (b) residual angulation on anteroposterior radiograph.

\section{Results}

The mean age of the patients was $8.8 \pm 3.1(5-15)$ years, 21 (72\%) of them were male and eight (28\%) were female. The mean follow-up period was $17.4 \pm 6.7(12-30)$ months. The mean casting time was $6.5 \pm 0.7(5-8)$ weeks. Long arm cast was applied meanly $3.9 \pm 0.4(3-5)$ weeks, and short arm cast $2.6 \pm 0.5(2-4)$ weeks.

Eighteen patients had isolated distal radius fractures and 11 had (38\%) associated distal ulna fracture. Thirteen fractures (45\%) were on the dominant side and 16 fractures $(55 \%)$ were on the non-dominant side. No complaints of pain were observed in any patient. All patients were able to perform daily and sportive activities without any problems. Parents were satisfied with the results. Compared to the healthy side, in 24 (83\%) patients, there were no limitations on wrist movements. Nonetheless, in two cases (7\%) and in three cases $(10 \%), 5^{\circ}$ and $10^{\circ}$ of pronation limitation was detected, respectively. In patients with re-displacement, the mean displacement occurrence time was $13.3 \pm 4.9(7-21)$ days.

The mean radial-ulnar angulation on the AP radiographs of 16 patients was $20.5 \pm 8.5\left(8^{\circ}-39^{\circ}\right)$ when the cast was removed, while the final angle decreased to $0.25 \pm 1\left(0^{\circ}-4^{\circ}\right)(\mathrm{p}<0.01)$. The mean amount of radial angulation in the lateral radiographs of 27 patients was $25 \pm 8.9\left(5^{\circ}-45^{\circ}\right)$ when cast was removed. At the last follow-up, this angulation was measured as $3.7 \pm 4.2\left(0^{\circ}-12^{\circ}\right)(\mathrm{p}<0.01)$. The translational amount in AP and lateral radiographs was $54 \% \pm 31 \%(10-100 \%)$ at the time of cast removal, $26.3 \% \pm 14.3 \%(10-60 \%)$ at three months and fully remodeled at the end of sixth month $(\mathrm{p}<0.01)$. It was observed that the translations on AP and lateral radiographs of all patients were completely remodeled at the sixth month $(\mathrm{p}<0.01)$ (Table 1$)$ (Figures 3, 4). 


\section{Cureus}

\begin{tabular}{|c|c|c|c|c|c|}
\hline & $\begin{array}{l}\text { At the time of } \\
\text { cast removal }\end{array}$ & $\begin{array}{l}\text { Difference between } \\
\text { cast removal - 3rd } \\
\text { month }^{\circ}(p)\end{array}$ & $\begin{array}{l}\text { Difference between } \\
\text { 3rd month - 6th } \\
\text { month }^{\circ}(p)\end{array}$ & $\begin{array}{l}\text { Difference between } \\
6 \text { th month - final } \\
\text { control }^{\circ}(p)\end{array}$ & $\begin{array}{l}\text { Difference between } \\
\text { cast removal - final } \\
\text { control }^{\circ}(p)\end{array}$ \\
\hline $\begin{array}{l}\text { Coronal plane } \\
\text { angulation } \\
(n: 16)\end{array}$ & $\begin{array}{l}20.5 \pm 8.5(8- \\
39)\end{array}$ & $\begin{array}{l}5.7^{\circ} \pm 3.39(2-12)(p: \\
0.04)\end{array}$ & $\begin{array}{l}5.9^{\circ} \pm 2.77(2-12)(p< \\
0.01)\end{array}$ & $\begin{array}{l}4.65^{\circ} \pm 3.34(2-13)(p< \\
0.01)\end{array}$ & $\begin{array}{l}16.25^{\circ} \pm 7.57(8-33)(p< \\
0.01)\end{array}$ \\
\hline $\begin{array}{l}\text { Sagittal plane } \\
\text { angulation } \\
(\mathrm{n}: 27)\end{array}$ & $\begin{array}{l}25 \pm 8.9(5- \\
39)\end{array}$ & $\begin{array}{l}7.5^{\circ} \pm 3.72(2-15)(p< \\
0.01)\end{array}$ & $\begin{array}{l}6.8^{\circ} \pm 3.26(2-16)(p< \\
0.01)\end{array}$ & $\begin{array}{l}4.8^{\circ} \pm 3.39(1-13)(p< \\
0.01)\end{array}$ & $\begin{array}{l}19.1^{\circ} \pm 8.62(0-32)(p< \\
0.01)\end{array}$ \\
\hline $\begin{array}{l}\text { Translation in } \\
\text { any plane } \\
(n: 20)\end{array}$ & $\begin{array}{l}54 \% \pm 31.01 \\
(10-100)(p< \\
0.01)\end{array}$ & $\begin{array}{ll}26.3 \% \pm & 14.33 \\
(10- & 60)(p< \\
0.01) & \end{array}$ & 0 & 0 & 0 \\
\hline
\end{tabular}

TABLE 1: Remodeling of angular and translational deformities.

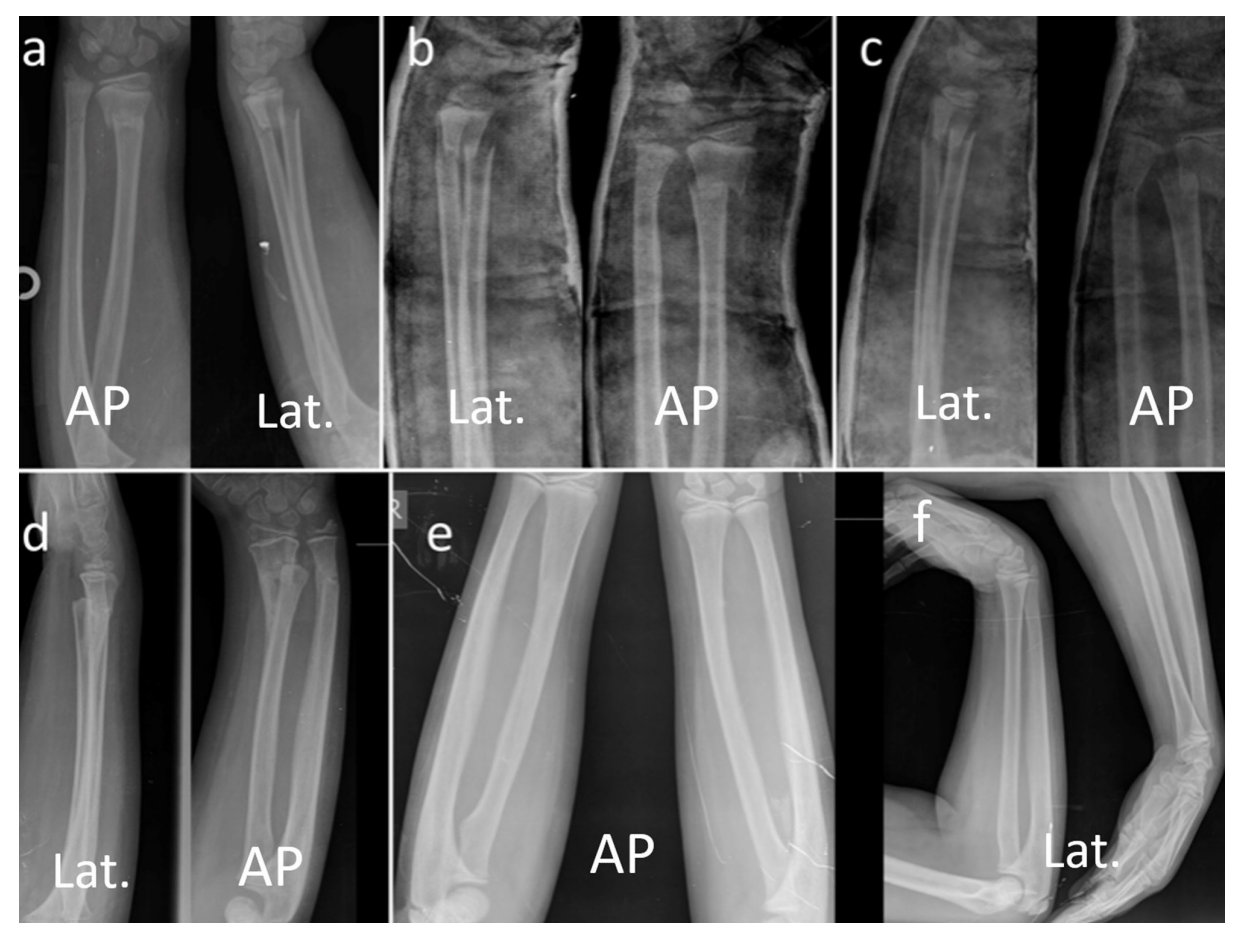

FIGURE 3: Case \#1. Serial radiographic examination of seven-year-old girl with distal radial metaphyseal fracture. (a) Initial radiograph on admission. (b) Immediate closed reduction, the angulations were in acceptable range in both planes. (c) Re-displacement in cast. (d) Radiographs after the cast removal. (e,f) Final comparison radiographs with the un-injured side at 30th month showing full remodeling and normal alignment.

AP: Antero-posterior; Lat.: Lateral. 


\section{Cureus}

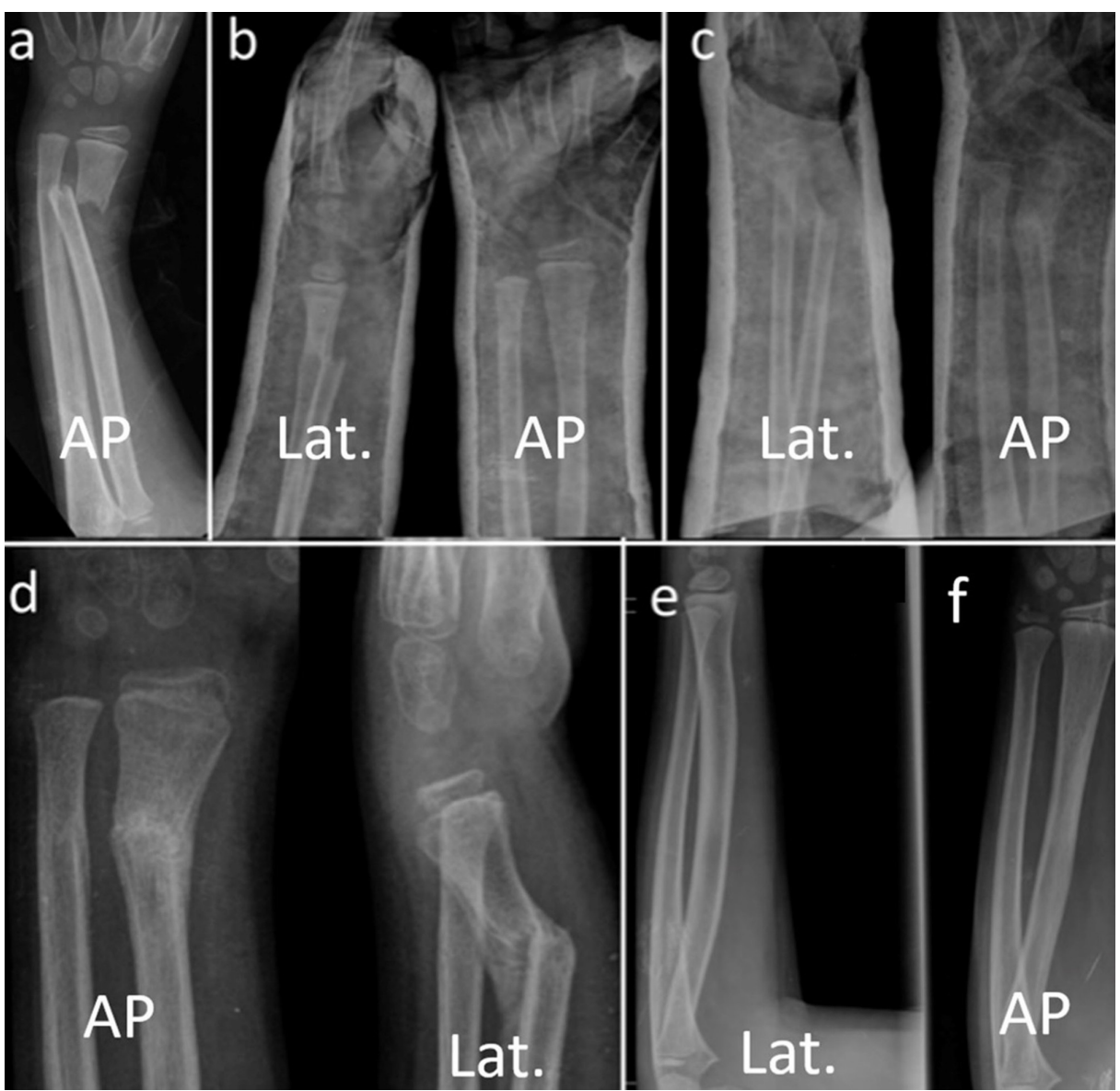

FIGURE 4: Case \#2. Serial radiographic examination of eight-year-old girl with distal radial metaphyseal fracture. (a) Initial radiograph on admission. (b) Immediate closed reduction, the angulations were in acceptable range in both planes. (c) Re-displacement in cast. (d) Radiographs after the cast removal. (e,f) Final radiographs at 30th month showing full remodeling and normal alignment.

AP: Anteroposterior; Lat.: Lateral.

\section{Discussion}

Distal $1 / 3$ fractures of the forearm constitute $20 \%$ of all pediatric fractures [1,2]. In children, closed reduction and casting are accepted as a fundamental approach in the treatment of distal radius fractures $[1,2,6]$. The distal physis of radius is responsible for the $75-80 \%$ of longitudinal growth which closes between the ages of 14 and 16. It has been stated that if the distal physis of radius is not injured, very prominent angles and displacements can be corrected [9]. As a result, the extent of acceptance of the deformities within the cast is also widened, especially since axial deformations have spontaneous recovery potential [6,10-12].

There are different opinions about the quality of reduction and how much angulation can be accepted in distal $1 / 3$ radius fractures. Under the age of 10 , it has been stated that $10^{\circ}$ to $50^{\circ}$ sagittal plane angulation and $10^{\circ}$ to $40^{\circ}$ coronal plane angulation can be accepted $[1,2,6,7,9,13-17]$. In distal radius fractures, the data of the studies as to the acceptable deformity limits are given in Table 2. 


\section{Cureus}

\section{Distal one-third fractures}

Fuller and McCullough, 1979 [16]

Larsen et al., 1988 [14]

Roy, 1989 [15]

Wilkins and O’Brien, 1996 [1]

Zimmermann et al., 2004 [13]

Roth et al., 2014 [17]

\section{Acceptable angular deformities (years: y)}

\section{$20^{\circ}(<14 y)$}

$28^{\circ}$ angulation ( $\left.\leq 11 \mathrm{y}\right)$

$16^{\circ}$ radial deviation $20^{\circ}$ dorsal angulation

$30^{\circ}-35^{\circ}$ (sagittal plane)

$10-\quad 15^{\circ} \mathrm{dorsal} / \mathrm{volar}$ angulation $(<9 \mathrm{y})$

$30^{\circ}(<9 \mathrm{y}) / 25^{\circ}(9-<12 \mathrm{y}) / 20^{\circ} \geq 12 \mathrm{y}$

TABLE 2: Publications about acceptable angulation limits.

Larsen et al. reported that the results of dorsal angulation of up to $20^{\circ}$ and radial angulation up to $15^{\circ}$ in children under nine years were good. They also reported that remodeling in children over 11 years of age was achieved by changing the orientation of the epiphysis plaque [14]. Wilkins-O'Brien indicated that 30-35 degree sagittal plane angulations would improve in children with a growth potential of at least five years [1].

Re-displacement rates following closed reduction in distal radius fractures have been reported to be $7-25 \%$ $[12,18,19]$. In pediatric population, fractures of the distal metaphyseal radius rarely cause functional deficiency because of high remodeling capacity. Significant improvements can be expected even in deformities which are not in main movement axis of the wrist such as radial deviation. In some studies, it has been reported that there is limitation in forearm rotation [7,8,20]. Roberts demonstrated that radial deviation of the distal fragment caused loss of forearm rotation [7]. They argued that this may be due to the narrowing of the interosseous space at fracture site. Högström et al. noted that there is a strong correlation between residual angular deformities and loss of forearm rotation [8]. In contrast, Nilsson and Obrant reported that forearm rotation loss is due to the initial displacement of the fracture, even anatomic reduction had been achieved after closed reduction [20].

Roberts compared the forearm motion ranges of both forearms in 50 healthy children without fractures and showed that forearm rotational movements may differ by up to $15^{\circ}$ even in healthy individuals [7]. For this reason, they accepted the values above $15^{\circ}$ of rotational loss as limitation in their work. In our study, there were no limitations on the motion of the wrist, except for the pronation. Pronation was limited in five patients. Limitations were $5^{\circ}$ and $10^{\circ}$ in two and three patients, respectively. Four of the five patients with limited pronation had residual dorsal angulations between $5^{\circ}$ and $10^{\circ}$ at their last follow-up. There was no radial angulation in any of the patients.

In a retrospectively designed study of 105 children with distal radius fractures, Jordan and Westacott reported that re-displacement is possible if optimal reduction (less than $10 \%$ translation and less than $10^{\circ}$ angulation) could not be performed. Especially in patients with more than $50 \%$ translations, it is suggested that the possibility of re-displacement is elevated and therefore it is necessary to fix the fracture by a Kirschner wire in these patients [21]. The results of our study do not support the findings of aforementioned study. Even in patients with more severe displacement, the radius is remodeling and does not constitute an altered function.

Zimmermann et al. compared the fractures healed with volar and dorsal angulations. Mean follow-up of time was 10 years, it was reported that there was no difference between the two groups in terms of radiological improvement in patients with an average of 15 degrees volar and dorsal angulation. There was a significant level of supination limitation in patients with volar angulation. This was also attributed to the distal segment in pronation in the volar displaced fractures [13].

Zimmerman et al., in their study of 10 years of 220 patients with distal radius fracture treated conservatively, reported that residual deformity under 10 years did not affect the long-term outcome, and angular deformity above $20^{\circ}$ and over half of the bone diameter adversely affected the outcome over the age of 10 years [22]. Roy reported that complete remodeling was achieved at displacements of $16^{\circ}$ on the AP plane and $20^{\circ}$ on the lateral plane, and there was no necessity for re-reduction maneuver for these patients [15]. Similarly, Hove and Brudvik reported that the results were excellent in 88 patients healed with deformity and conservative treatment was the gold standard for distal radius fractures [6]. In this study, all translations below and above 10 years of age improved clinically and radiologically. Neither patient had functional limitation.

Do et al. stated that $15^{\circ}$ of angulation in any plane and up to $1 \mathrm{~cm}$ shortening were completely remodeled in 7.5 months in 34 re-displaced and angulated fractures. Functional impairment was not reported in any 
patients [23]. Short or long arm cast applications have been discussed in these fractures, but no difference was found in complications between the applications [24]. Despite the fact that all our cases were treated with long arm cast, re-displacement has occurred. We believe that re-displacement is not associated with above or below elbow casting.

There are some limitations to our study, of which the retrospective study design is probably the most important, and patients' number is low.

\section{Conclusions}

In conclusion, the present study demonstrates that radial and dorsal angular deformities up to $39^{\circ}$ and $22^{\circ}$ volar angulations and complete displacement correct fully in children up to 10 years old. In children between 10 and 15 years, the dorsal angulations up to $38^{\circ}$, radial angulations up to $23^{\circ}$, and volar angulations up to $16^{\circ}$ are acceptable for remodeling capacity of the child.

\section{Additional Information \\ Disclosures}

Human subjects: Consent was obtained by all participants in this study. Tepecik Education and Research Hospital Ethics Committees for Research issued approval 2017-234-22. The study protocol of this retrospective research has been approved by the Ethics Committee of the same institution where the study was conducted. Animal subjects: All authors have confirmed that this study did not involve animal subjects or tissue. Conflicts of interest: In compliance with the ICMJE uniform disclosure form, all authors declare the following: Payment/services info: All authors have declared that no financial support was received from any organization for the submitted work. Financial relationships: All authors have declared that they have no financial relationships at present or within the previous three years with any organizations that might have an interest in the submitted work. Other relationships: All authors have declared that there are no other relationships or activities that could appear to have influenced the submitted work.

\section{References}

1. Wilkins K, O’Brien E: Fractures of the metaphysis of the distal radius and ulna . Fractures in Children. Rockwood CA, Wilkins KE, Beaty JH (ed): Lippincott-Raven, Philadelphia; 1996. 1:486-487.

2. Tachdjian MO: Growth and development. Tachdjian's Pediatric Orthopaedics. Herring JA (ed): W.B. Saunders, Philadelphia; 2002. 1:3-21.

3. Herring JA: Tachdjian's Pediatric Orthopaedics . Herring JA (ed): W.B. Saunders, Philadelphia; 2002.

4. Haddad FS, Williams RL: Forearm fractures in children: avoiding redisplacement . Injury. 1995, 26:691-692. 10.1016/0020-1383(95)00136-0

5. Bailey DA, Wedge JH, McCulloch RG, Martin AD, Bernhardson SC: Epidemiology of fractures of the distal end of the radius in children associated with growth. J Bone Joint Surg Am. 1989, 71:1225-1231. 10.2106/00004623-198971080-00016

6. Hove LM, Brudvik C: Displaced pediatric fractures of the distal radius . Arch Orthop Trauma Surg. 2008, 128:55-60. 10.1007/s00402-007-0473-X

7. Roberts JA: Angulation of the radius in children's fractures . J Bone Joint Surg Br. 1986, 68:751-754. 10.1302/0301-620X.68B5.3782237

8. Hogstrom H, Nilsson BE, Willner S: Correction with growth following diaphyseal forearm fracture . Acta Orthop Scand. 1976, 47:299-303. 10.3109/17453677608991994

9. Pannu GS, Herman M: Distal radius-ulna fractures in children . Orthop Clin North Am. 2015, 46:235-248 10.1016/j.ocl.2014.11.003

10. Younger AS, Tredwell SJ, Mackenzie WG: Factors affecting fracture position at cast removal after pediatric forearm fracture. J Pediatr Orthop. 1997, 17:332-336.

11. Mabrey JD, Fitch RD: Plastic deformation in pediatric fractures: mechanism and treatment . J Pediatr Orthop. 1989, 9:310-314.

12. Zamzam MM, Khoshhal KI: Displaced fracture of the distal radius in children: factors responsible for redisplacement after closed reduction. J Bone Joint Surg Br. 2005, 87:841-843. 10.1302/0301620X.87B6.15648

13. Zimmermann R, Gschwentner M, Pechlaner S, Gabl M: Remodeling capacity and functional outcome of palmarly versus dorsally displaced pediatric radius fractures in the distal one-third. Arch Orthop Trauma Surg. 2004, 124:42-48. 10.1007/s00402-003-0552-6

14. Larsen E, Vittas D, Torp-Pedersen S: Remodeling of angulated distal forearm fractures in children . Clin Orthop Relat Res. 1988, 237:190-195.

15. Roy DR: Completely displaced distal radius fractures with intact ulnas in children . Orthopedics. 1989, 12:1089-1092.

16. Fuller DJ, McCullough CJ: Malunited fractures of the forearm in children . J Bone Joint Surg Br. 1982, 64:364367.

17. Roth KC, Denk K, Colaris JW, Jaarsma RL: Think twice before re-manipulating distal metaphyseal forearm fractures in children. Arch Orthop Trauma Surg. 2014, 134:1699-1707. 10.1007/s00402-014-2091-8

18. Joseph B: Fractures of the forearm bones. The Growing Hand: Diagnosis and Management of the Upper Extremity in Children. Gupta A, Kay SPJ, Scheker LR (ed): Mosby, London; 2000. 567-581.

19. Voto SJ, Weiner DS, Leighley B: Redisplacement after closed reduction of forearm fractures in children . J Pediatr Orthop. 1990, 10:79-84. 10.1097/01241398-199010010-00015 


\section{Cureus}

20. Nilsson BE, Obrant K: The range of motion following fracture of the shaft of the forearm in children . Acta Orthop Scand. 1977, 48:600-602. 10.3109/17453677708994804

21. Jordan RW, Westacott DJ: Displaced pediatric distal radius fractures--when should we use percutaneous wires?. Injury. 2012, 43:908-911. 10.1016/j.injury.2012.01.006

22. Zimmermann R, Gschwenter M, Kralinger F, Arora R, Gabl M, Pechlaner S: Long term results following pediatric forearm fracture. Arch Orthop Trauma Surg. 2004, 124:179-186. 10.1007/s00402-003-0619-4

23. Do TT, Strub WM, Foad SL, Mehlman CT, Crawford AH: Reduction versus remodeling in pediatric distal forearm fractures: a preliminary cost analysis. J Pediatr Orthop B. 2003, 12:109-115. 10.1097/01.bpb.0000043725.21564.7b

24. Webb GR, Galpin RD, Armstrong DG: Comparison of short and long arm plaster casts for displaced fractures in the distal third of the forearm in children. J Bone Joint Surg Am. 2006, 88:9-17. 10.2106/JBJS.E.00131 